\title{
Design Faz Tecnologia Criativa?
}

\author{
Eduardo Lopes*
}

1. Por que Design? 2. Politlca de Criatividade Tecnológica. 3. Criatividade - Cibernética - Tecnologia. 4. Um Parentesis: Heuristica e Criatividade. 5. Design... Caráter interdisciplinar e Criatividade. 6. Amplitude da Criatividade $\times$ Desenvoivimento. 7. O Design e a Empressa. 8. Exportaçáo - Tecnologia Mercadológica. 9. O Produto - Entidade Autónoma. 10. Proposiçăo. 11. Terminologia. 12. Sintese Proposicional. 13. Nota sobre Sintese Proposional. 14. Conclusăo.

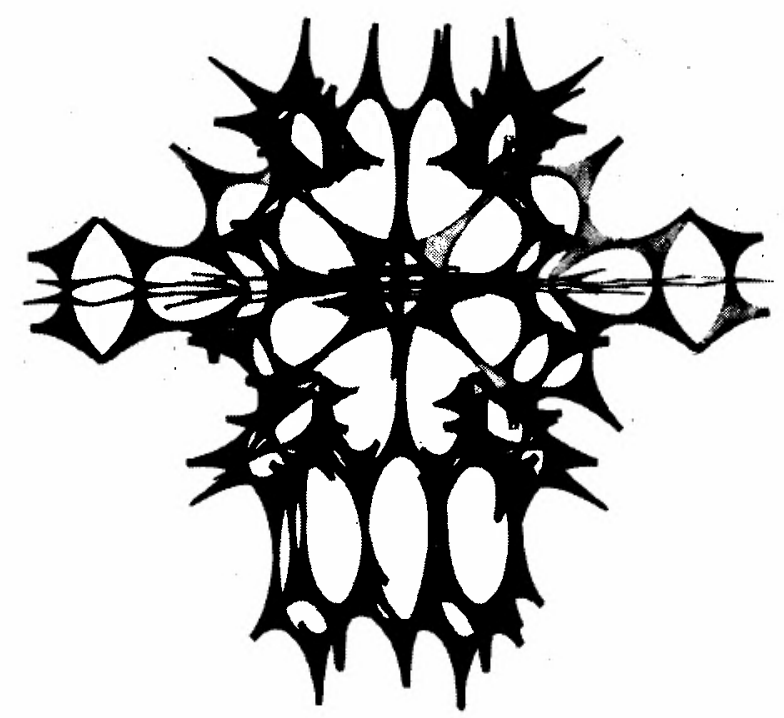

1. Por que Design?

Do ponto de vista das atividades econômico-sociais, talvez a maior responsabilidade do design seja introduzir uma nova dinamica desenvolvimentista. E não o poderia deixar de ser, já que sua atividade se processa tipicamente à base de inovação e criação. No momento, o melhor produto do desenho industrial em nosso pais será o próprio desenho

Professor titular da cadeira de Desenho Industrial da F.U.M.A., Minas Gerals, Professor de Criatlvidade da Faculdade de Comunicaçáo Publicitála, Săo Paulo, e Professor de Anállse e de Iniciaçăo às Técnicas industrials da FEBASP - Formação. de Professơres, Săo Paulo.

R. Adm. Emp., Rlo de Janeiro,

Industrial condizente com a realidade brasilelra. Afinal, o desenho industrial também corre o risco de tornar-se a mais recente importação, pois a índole geral de nossa conjuntura cultural não crê na geração espontânea, natural ou artificial dos conceitos e pensamentos válidos.

Esta autêntica modéstia de princípios está francamente patenteada em nossa história. Eis que somos vítimas a cada momento da importação de conceitos alienados de nossa realidade. Apelamos para uma reaçāo em tôdas as áreas, pois ela se faz urgente e imperativa.

O govêrno federal deve preocupar-se sériamente com 0 produto nacional. Outros países o fazem sistemàticamente. A exemplo, assinalamos o prẻfácio do livro Mado in Germany, endossado pelo dr. Ludwig Erhardt, ex-chanceler da República Federal da Alemanha, que, a determinada altura, afirma: “... Esta reputação (do produto nacional) deve ser mantida a custo de qualquer esfôrço". A obra ainda assinala os fatôres genéricos que concorrem para o sucesso do produto alemão e destaca a forma como o fator mais decisivo dentre êles. A nós caberia um procedimento semelhante? Vale a pena estabelecer uma filosofia de made In Brazili? Tal orientação corresponderia à realidade qualificativa do original estrangeiro? Diremos que sim, se a

11(1): 95-106

Jan./Mar. 1971 
expressāo made in Brazil corresponder, em têrmos de linguagem universal, a uma conscientização nacional da necessidade de identificar o produto nacional autêntico, cujas raízes criativas tenham origem dentro dos limites do nosso território. No entanto, a divulgação franca do dístico fabricado no Brasil, que comumente encontramos nos produtos resultantes de implantação fabril em nosso pais de empreendimentos estrangeiros, simula uma satisfação não verdadeira. E que tais produtos não são originados de um esfôrço de criatividade nacional. Não queremos negar os benefícios de implantação de indústrias mistas de capital nacional e estrangeiro. Sabemo-la necessária em muitos casos. Mas aos responsáveis pelo desenvolvimento econômico-social, cumpre integrar em suas equipes o desenhista industrial nacional e fornecer-lhe ambiente próprio para o melhor desenvolvimento de seu trabalho no interésse geral. Portanto, não nos referimos à submissão do desenho industrial à realidade, ao status, mas à colocação do design em condições de imprimir com realismo um impulso diferenciado à temática do desenvolvimento nacional. Numa linguagem essencial e especificamente profissional, propomo-nos a desenvolver esta questão em nosso trabalho.

O fato é que uma nova profissão está sendo introduzida em alguns estados do Brasil, sem que uma conscientização se processe em todo o sistema público-privado, no intuito de aceitá-la como interessante e realmente válida para o progresso do país: a do desenhista industrial. Cumpre provocar uma atitude nacional favorável à importância da criação. Isto se faz mister, já que o país ignora as vantajosas conseqüéncias econômicas e sociais do incremento da criatividade em todos os niveis. A criatividade pode ser vista como o potencial elaborativo-inovacional, ou a capacidade de um povo de criar, e mesmo acatar inovaçóes. Sempre fomos pouco dados ao aproveitamento $\theta$ beneficiamento daquele potencial, e por isso mesmo, arcamos com as conseqüências da necessária importação de idéia e know-how.

"Nem os exércitos, nem os capitais, ou riquezas naturais, são marcas do poderio, mas a capacidade de imaginar e criar." 1 Está implícita, é claro, a capacidade de gestão criativa. Numa comparação mais ou menos objetiva, podemos colocar a criatividade como capaz de produzir rendimentos muito superiores à capacidade de uma nação em explorar suas próprias riquezas naturais. Isto porque, até mesmo para explorá-las são necessárias as inovações.

No momento, portanto, cabe assinalar que no processamento do design, duas tendências profissionais concorrem para a sua edificação: a tecnologia e a criatividade; elas respondem à necessidade de integração, porque são paralelas entre si e ampliam-se suas possibilidades quando de suas múltiplas e tensoriais relações. Digo tensoriais, porque de um modo geral, às iniciativas numa destas áreas deve corresponder sempre uma reação na outra, uma imagem de retroalimentação. Por exemplo: um nôvo material criado implica novos produtos (criatividade); mas o oposto também é verdadeiro, isto é, a necessidade de se desenvolver novos produtos conduz às descobertas de laboratório (tecnologia). A ampliação em larga escala desta dinâmica, a sua extensão política, faculta o desenvolvimento auto-sustentado.

\section{Política de criatividade tecnológica}

Enumeramos, a seguir, as justificativas à sugestão que fazemos no sentido de se seguirem providências que possibilitariam a implantação da política de criatividade tecnológica:

1ą) Criação de um Ministério de Criatividade Tecnológica (MCT). Como algumas de suas providéncias $\theta$ atribuições, destacamos:

a) vinculação do atual Instituto Nacional da Propriedade Industrial (antes DNPI)

1 SCHREIBER, J. J. S. O deaaflo americano. p. 273. 
ao MCT e sua total dinamlzação em têrmos de Criatividade Tecnológica $\theta$ design.

b) assistência técnica geral - informação.

c) pesquisas de consumo e comunicação.

2a) Instituição obrigatória da cadeira de criatividade em todos os niveis escolares, inclusive superiores e cursos de pós-graduação. 2

3a) Institulção de um sistema de estímulo fiscal, para empressas que porventura façam investimento em criatlvidade tecnológica.

Para melhor entendimento da amplitude do conceito, vale dizer que, do ponto de vista político-social e cultural, as regiōes não evoluldas devidamente, o são porque carecem de criatividade. Dal, possivelmente, se pode deduzir sua importância estratégica; e falamos então de criatividade política, um tema em aberto!... Afinal, até hoje desconhecemos uma idéia realmente original que tivesse sido capaz, em nosso caso particular, de promover uma integração, sempre resultando disso um escoamento de interésse para uma outra área de gravitação ideológica, fato inevitável quando não se têm idéias próprias.

Num enfoque regional, a SUDENE nos faz lembrar uma situação clássica de contradição e dúvida desenvolvimentista. A situação ali seria outra se se estabelecesse um amplo programa de criatividade. Realmente fala-se muito em falhas, "principalmente no que concerne aos Departamentos de Industrialização e de Recursos Humanos. A verdade é que as discutidas teses sôbre aspectos de investimento, implantando indústrias em estágio avançado de desenvolvimento tecnológico, alta mecanização e mesmo automatização, numa região onde impera a ociosidade humana, cria problemas de desemprégo, agravado pela afluéncia de contingentes de população, principalmente trabalhadores atrai-

2 Pouco antes do Sr. Jarbas Passarinho tornar-se ministro da Educaçáo em meados de 1969, tivemos a oportunidade de the falar na Delegacia Regional do Trabalho, em Săo Paulo, sôbre "... uma proposta de criatividade tecnológica".

Janeiro/Março 1971 dos pelo rumor da implantação de novas indústrias. A observaçăo é válida para muitas outras regiōes e, quem sabe, para o pais como um todo. Afinal, o processo mesmo de substituição de importações se fêz, como é sabido, a baixo indice de absorção de mão-deobra. E um critério de eficiéncia $\theta$ integração. Longe, entretanto, de serem absorvidos pelo campo de trabalho, permanecem disponiveis; eis que são poucos os aproveitados pela nova fábrica. Outro problema, que deve preocupar todo brasileiro, é o da necessidade de se dar mais atenção ao produto autóctone, fruto de criatividade (invençōes), tal como em países desenvolvidos da Europa, nos EUA, algumas nações orientais. Afinal, indústrias devem ser implantadas de preferéncia segundo produtos criados e registrados em nosso território. Ambos os enfoques, integração vertical e horizontal, se traduzem num embate entre duas correntes e sua harmonização. Estas duas correntes, reafirmamos, são: criatividade e tecnologia.

\section{Estabeleçamos um paralelo:}

1.a) A criatividade se processa mediante a elaboração de formas e sistemas nos campos da habitabilidade, vivência, bemestar e comunicação humana, inovando em suas estruturas.

1.b) A tecnologia se desenvolve, segundo a pesquisa e descoberta das leis racionais - sua aplicação, quer no campo dos mecanismos, quer no das estruturas, aqui consideradas face à máquina ou à própria vida. E o caso das pesquisas cibernéticas, por exemplo.

2. a) Constitui tóda a faixa formada pela pragmatização da arte, do cinema, da música, do teatro, da arquitetura, do desenho industrial, das atividades literárias, das gráficas, da publicidade em geral, o suas ramificações.

2.b) Compreende tôda a faixa onde se acham envolvidas tanto a investigação cientifi$c a$, como a engenharia em seus diversos 
ramos, as atividades econômico-administrativas e profissões afins.

3. a) Profissionalmente, também, desenvolve relações graduais desde o nivel superior; manifesta-se nos escalões médios e Dcorre também entre trabalhadores simples, especializados. Em todos esses niveis, $O$ individuo assume $o$ papel de inventor.

3.b) Idem. Profissionalmente, possui todos os escalöes, desde o superior aos niveis técnicos e inferiores.

Esta colocação, porém, merece alguns reparos quanto à arquitetura $\theta$ ao desenho industrial; ambos assumem, por vêzes, uma conotação ambigua e envolvente numa área comum, de grande afinidade; algo que se poderia definir como uma teconologia ambiental. Mas no Brasil, como veremos mais adiante, a preocupação maior deve ser outra.

Como pragmatização sistemática da ciência, a tecnologia busca o beneficiamento das descobertas científicas. A tecnologia, como ciência, se processa por uma forma de pensamento especialmente dedutivo, quer a proposição inicial seja abstrata ou resulte da observação de um fenômeno natural. Por outro lado, a criatividade é uma pragmatização da capacidade artística, $\dot{\theta}$ indutiva e propositiva. E forçoso salientar que esta é uma conceituação técnica devidamente esclarecida e reconhecida por todos; reafirmamos, no entanto, sua validade.

\section{Criatividade - Cibernética - Tecnologla}

O que nos parece, porém, mais interessante neste paralelo (criatividade-tecnologia) é o seu efeito de retroalimentação. E que, por um lado, faculta maior iniciativa de pesquisas $\theta$, por outro, conduz tais pesquisas a bons têrmos. São dois meios distintos, sem dúvida, mas que unidos compõem um par bastante dinåmico. Em meados de 1969 fizemos uma proposta ao IPT - Instituto de Pesquisas Tecnológicas de São Paulo, sugerindo tal dinâmica. Em verdade, um órgáo de pesquisas estrutu- rado neste processo híbrido assume a proporção de um sistema que é, por si mesmo, autosustentável. Tal sistema faculta um ciclo em duplo sentido do material à forma; ou da forma à pesquisa do melhor material condizente com suas necessidades. Por fim, estabelecese o fluxo informativo bidirecional, como se deduz da Clbernética e Sociedade. ${ }^{3}$ E como se neste particular o IPT se tornasse cliente de si mesmo.

\section{Um parêntesis: hourística $\theta$ criatividade}

Algo semelhante àquele binômio ocorre também em nosso cérebro. Bem no fundo de nosso cérebro, em algum recanto obscuro da mente, um complexo sistema emissor $\theta$ receptor televislonal funciona independentemente da nossa vontade. $O$ pensar não independe désse aparelhamento. Poderiamos denominar ésse nível de captaçăo, de metapercepção e meta-emissão, as origens da arte e da criatividade. Mas cada idéia é, a cada momento, uma forma de pensamento. Isto quer dizer que no ato de pensar deve concorrer a globalidade mental e psíquica e a totalidade informativa; é tôda a massa fluida que se conforma $\theta$ deforma em pontos tensoriais. $O$ espaço converge e se afunila sob tensão criando bolsōes. A criatividade como processo se diferencia da heurística por ser ela um subsistema e a heurística, uma estruturação final. A questão da dinâmica da modelaçăo cerebral (heurística), segundo novas teorias cibernéticas, torna-se altamente complexa, pois neia se aplica tóda uma geometria euclidiana ao espaço mental, pois êste assume curvaturas positivas, negativas ou reversas; além disso, essa conformação é mutável a todo instante, é uma topologia mental a exigir percepção e visualização espacial. Criativamente, uma idéia é uma polarização, um sistema gravitacional global; explicamos: nossa mente é um espaço cósmico, onde perambulam corpos (informações); quando uma informa-

3 WIENER, N. Clbemótica e cocledade. p. 49. 
ção maior ou acentuadamente enfatizada se coloca estratègicamente face a um determinado repertório, ela cria no espaço, uma polarização ou uma convergência, isto é, passa a existir um sistema gravitacional. Este sistema bem pode ser uma idéia complexa. Assim, podemos descrever a criatividade como sistema, o qual ocorre em nivel profundo, sincrético e subconsciente.

A heuristica se parece com um processo decisório em que se subentende uma situação estabelecida (ou preestabelecida); ela envolve uma decisāo a tomar diante de um bit, 4 uma opçăo imprevisível. A luz da teoria da informação, a inovação pode ser entendida como uma informação com alto grau de imprevisibilidade, tal como um ruido num canal; êle será tanto mais informativo quanto menos previsivel naquele canal. A informação deslocada de seu contexto passa a constituirse em inovação. Parece-nos que a heurística faculta solução de problemas imprevisiveis, mas criatividado implica cría-los, ou seja, alterar o processamento informático subconsciente.

O reconhecimento dinåmico, inicio do processo heuristico, é na realidade, o fim da fase de processamento subliminar ou do nivel sincrético ${ }^{5}$ de elaboraçăo.

\section{Design... carater interdisciplinar criatividade}

O design estabelece a malha de relações: é uma estruturação profissional. Cumpre ainda examinar as múltiplas interaçōes do processo quando a tecnologia pode ser criativa. Prevalece, entretanto, o princípio básico que a orienta: a descoberta. $O$ oposto também é verdadeiro, isto é, a criatividade pode manifestar-se tecnológicamente, especialmente quando se fala de uma metodologia sistemática da criatividade, o que talvez corresponda ao conceito de design. Afinal, design é

\footnotetext{
4 As origens do bit inconsciente săo desconhecidas. - livro Heuristica, de Puchkin, aponta a modelaçăo como uma atividade auto-reguladora (p. 100).
}

5 Sincrético, ou seja, subestruturado. entendido como a especialização em Idélas globais, o que nos parece uma qualidade interessante também ao administrador de emprêsas a quem interessa estudos de criatividade ou da teoria do design.

Ademais, a criatividade envolve um conceito infra-estrutural, do que não podem prescindir as profissões modernas, especialmente a do desenhista industrial. Voltemos às considerações sôbre desenvolvimento.

\section{Amplitude da crlatlvidade $x$ desenvolvl- mento \\ E necessário deixar bem claro que o} que se propõe no presente trabalho é a compreensão de uma criatividade assentada em bases amplissimas, que envolvesse a própria atitude nacional, principalmente das altas esferas administrativas. Propõo-se uma contaminação geral. Isto porque vigora um conceito restrito de criatividade. Ainda mais quando se pretende criar a tecnologia nacional, própria, mais urgente se torna mobilizar as consciências no entendimento do caráter ambiguo dessa tecnologia. A séde de tecnologia deve ser atendida com imaginação $\theta$ iniciativa. Assim, tecnologia e criatividade stó como os dois hemisfórios de uma mesma esfora. Decisivamente o desenho industrial é a sintese entre ambas.

Lembrando aqui os relatórios das comissões de tecnologia do govêrno do Estado de São Paulo, chamamos a atenção para a énfase que se deu, em certas fases, aos estudos da tecnologia mercadológica. E verdade que 0 desenho industrial foi ali assinalado como fator de incremento désse ideal. Mas existe uma grande resistência por parte da sociedade, das classes dirigentes e da própria comunidade em reconhecer que é preciso ir ao encontro das novas profissóes. Nos relatórios posteriores nota-se, com pesar, uma certa omissão a êsses dinamicos aspectos da tecnologia. $E$, também, bastante válida a referência que as primeiras proposições daquelas comissões fazem ao problema das invençōes no estado. 
Este é um aspecto delicado do problema. Em nosso pais, falar em invençóes desperta, infelizmente, uma imagem com uma conotação pejorativa; quando não, assume-se uma atitude paternalista, como se 0 individuo criativo fôsse digno de comiseração. Como exemplo, basta verificar 0 que ocorre com os órgãos dedicados ao amparo, à assistência ao inventor. E simplesmente degradante. $O$ que se faz é muito pouco, não tem sentido. Há mesmo - perigo de uma tecnologia vir a favorecer, no Brasil, ùnicamente aos já desenvolvidos por esfôrço de integração vertical. Pode tornar-se uma tecnologia tão importada $\theta$ alienante ao Brasil como certos tipos de empreendimentos que vieram a título de substituiçăo de importaçōes. Ao nosso pais seria possivel criar uma ampla rêde de indústrias manufatureiras? Imagine só, cobrando royalties, mercê de uma nova tecnologia! A imagem tem cabimento; não há de ser, porém, com a atual e absurda situação. E o velho problema da morosidade com que o DNPI (Departamento Nacional de Propriedade Industrial) vem efetuando os registros e as terriveis conseqüências désse atraso. Quando em 1968, o então presidente da ABAPI ${ }^{\circ}$ - Associação Brasileira dos Agentes da Propriedade Industrial - Dr. Custódio de Almeida, advertiu sóbre as conseqüências do atraso nos registros, que tomam cada vez mais um caráter desastroso e imprevisível, não encontrou um apoio maciço da parte dos interessados, como seria de se esperar. Lutar pela modernização do DNPI é uma campanha meritória que demanda de nossa parte todo o apoio.

No 11 ? Seminário Nacional de desenho industrial (maio de 1968, Belo Horizonte), 7 foi-nos possivel levantar debates em tórno dos problemas relativos ao interésse repre-

6 Numa série de debates realizados nas federaçōes industrials (Rio de Janeiro, Săo Paulo e Minas, dentre outras). Participamos das discussరos na Federaçăo das Indústrias de Minas Gerais (FIEMG), em 1968.

7 No il Seminário Nacional de Desenho Industrial (Belo Horizonte, maio de 1968) contamos com a presença de um representante da ABAPI lo seminário fol realizado também na FIEMG). Nosso pronunciamento sentado pela Legislação de Propriedade Industrial no Brasil, $\theta$ das consequeencias danosas da complexidade $e$ atraso nos registros, requerimento de patentes ou prioridade de fabricação. Não só porque desenhos industriais como invençð̃es em geral têm necessàriamente que ser registrados no DNPI, como também pelo fato de que ao design cabe reformular propostas inventivas, quer de origem particular, quer industrial, facultando-lhes por seus métodos aquelas qualidades formais que lhes garantirão sua plena realização como produto de série. Isto é tanto válido para invençōes mecânicas, como especialmente para modelos industriais, embalagens, símbolos ou marcas, ou mesmo processos. Isto tem uma finalidade maior, endógena, de desenvolvimento a partir de fatốres Internos, e não só exógena que é o desenvolvimento por pressão externa de novas tecnologias. (Administraçăo nos pai$s e s$ em desenvolvimento, de Fred W. Riggs, edição F.G.V.)

Precisamos salientar aqui uma linha de coerência com o pensamento de uma obra importante de nossos dias, Ideologia da socledade industrial, de Herbert Marcuse que, à página 61, nos diz da "introdução da tecnologia no's paises atrasados". Ele fala da "tradição e dos estillsmos autóctones que oferecem resisténcia àquela sobreposição de tecnologia". E mais, "... a revolução social, a reforma agrária e a redução do superpovoamento seriam requisitos, mas não a industrialização nos padróes das sociedades desenvolvidas" (o grifo é nosso).

O problema ainda consiste em fazer com que êsse desenvolvimento autóctone se proceda sem prejuizo do sistema implantado pelos dois grandes pólos mundiais, superdesenvolvidos, condição esta sine qua non de sua operacionalidade.

all fol no sentido de vincular o atual DNPI - Departamento Nacional de Propriedade Industrial - MIC - sua modernizaçăo, pela adoçăo do computador, ao MInistério da Tecnologia que na ocasižo se pretendia criar. Também pronunciamos a respelto do interésse que representaria um Ministério de Criatividade e Tecnologia - por seu valor altamente estratégico para 0 desenvolvimento nacional.

Revista de Administraçăo de Emprêsas 


\section{O design e a emprôsa}

Encarado sob determinados pontos de vista, cabe reconhecer a existência de certas barreiras ao desenvolvimento do desenho industrial. Em nosso caso, as dificuldades se iniciam pela avaliação do trabalho criativo. Afinal, empresários e designers iniciam agora um diálogo nesse sentido $e$ as perspectivas de um entendimento a curto prazo parecem um pouco duvidosas, exigindo afinal um esfôrço de boa vontade.

O sistema de royalties ou pagamento de percentuais constitui um método pouco divulgado e de difícil processamento em nosso meio devido à dificuldade de contrôle sóbre a produção e o mercado. Aliás, isto exige uma sistemática e legislação de propriedade industrial que, em nosso país, é inteiramente insatisfatória. "Uma reformulação naquele setor torna-se imperativo de primeira grandeza", reafirmamos. Outros problemas constituem fator de preocupação, tais como a inexistência de elementos profissionais de nivel médio, capazes de construir protótipos. Tal profissional atenderia ao designer, seu superior em cultura e capacidade criativa, imediatamente após o projeto ou nas fases de fermentaçăo e pesquisa. E que a indústria nacional normalmente não conta com empregados capacitados para tal e nem pode arcar com os onerosos custos dos protótipos. Sabemos que êsses custos podem atingir dezenas ou centenas de vêzes o preço de uma unidade produzida em série. Um setor a ser socorrido, portanto, é o da prototipia 8 (têrmo que propomos à falta de outro). E tem uma função estratégica, pois soluciona um duplo problema: o da potencialidade inovacional e o da capacidade elaborativa. Num pequeno enfoque, assinalamos o que uma atividade de prototipia pode fazer do ponto de vista humano ou social:

a) a integração de artesão e inventores entre si (mútua integração processo-inovação), e sua real colocação no campus experimental fabril. A título de exemplo, citamos os famosos carrozleres, construtores de avançadas linhas de veículos automotores. E melhor que estimular programas de artesanato.

b) formação e preparação de um nôvo tipo de elemento especializado, num programa de formação de mão-de-obra, com um enfoque preciso de tecnologia da forma nos diversos ramos dos modelos industriais.

c) faculta a primeira avaliaçăo de um nôvo produto proposto, permitindo a realização de um trabalho de profunda satisfação psicológica.

Do ponto de vista da indústria $e$ do mercado, o protótipo se presta ainda a estudos de pré-lançamento, isto $\dot{e}$, a construção (ou produção em pequena escala) de modelos com a finalidade precípua de testes mercadológicos, pesquisa de opinião ou em nível subliminar, de tendências, gostos e preferências do consumidor.

Assim como o desenho industrial promove a integração tecnologia-criatividade, a prototipia conduz também à sua integração num nivel médio e, por isso mesmo, mais imediato. A formação de prototipistas constitui a superação de uma grande dificuldade ao desenvolvimento do próprio desenho industrial, como da indústria, e por extensão, do produto nacional.

\section{Exportaçăo - tecnologia mercadológica}

Perguntemos se é possivel falar de diversificação e de exportação quando os produtos essencialmente nacionais não se acham devidamente evoluídos para uma tal conquista mercadológica. Falamos das qualidades formais que Ihes possibilitarão tão almejada penetração nos mercados externos em franca concorréncla, quando falta até mesmo a imagem da emprésa. Ali, especialmente, o produto deve ser, por si mesmo, a mensagem.

8 PROTOTIPIA - tóda atlvidade relacionada a execuçǎo de modelos, simulacros, testes em protótipos; uso de protótipos para efeito de pesquisa de mercado etc. 


\section{O produto - entidade autónoma}

Num enfoque essencialmente criativo, dentre os fatôres primordiais, contamos aquêle em que, no âmbito dos manufaturados $\theta$ bens de utilização em geral, o produto assume um caráter superior até mesmo à própria indústria. Em têrmos de desenho industrial brasileiro, cabe uma concieituação do produto como uma entidade absolutamente autônoma do mundo da produção. Isto quer dizer que devemos buscar uma colocação do problema, face à estratificação empresarial brasileira, ainda atomística em têrmos um tanto mais propositivos, com certo desprendimento e natural fluência criativa. Tais produtos devem superar o lapso do mútuo conhecimento, design-indústria, impossivel de ser resolvido a curto prazo, deslocando a atividade de criação do produto, forma ou modélo, para uma área transcendente, independentemento da emprêsa que o deverá adotar. $A$ emprêsa caberá, num esfórço de percepção e integração, inserir-se no sistema proposto, à medida de suas possibilidades operacionais, produção e mercado. E que os novos produtos ou modelos serão portadores de um potencial que lhes permita a abertura de amplas possibilidades mercadológicas, às quais as emprêsas se vincularăo parcial ou totalmente. Convém, naturalmente, nesses casos, a realização do projeto específico, envolvendo engenharia do produto e marketing dentro das novas coordenadas econômico-administrativas.

No Brasil, portanto, o desenho industrial ${ }^{\circ}$ deve suprir a falha criativa global, preencher o vazio, isto é, o desenhista industrial deve inventar, 10 êle próprio, sempre que possivel, as novas utilidades e destinações diversas do desenho industrial. Ou mesmo, através de grandes instituiçőes de pesquisa e desen-

9 Um nome grosseiro para uma atividade tão ampla e sutil.

10 Perdoem o têrmo invenģío colocado aqui; substitul-lo-emos logo adiante por outro mals interessante, face ao deslon. volvimento, planejar atividades; programas integrados $\theta$ grandes sistemas administrativos e económico-sociais, como, por exemplo, no planejamento de núcleos industriais (distritos ou cidades), no sentido de promover as atividades do potencial criativo-elaborativo local, mobilizando inventores e núcleos de produção semi-artesanal. Podemos denominar tal roteiro criatividade industrial. Sentimos necessário, enfim, que alguns dos nossos colegas de profissão, que possivelmente pensam de forma diferente, reflitam no fato de que na nossa conjuntura é preciso preocuparse menos com os poucos a grandiosos projetos $\theta$, em maior escala, com a deflagração de uma grande quantidade de pequenos $e$ médios empreendimentos. Mas uma atividade assim indireta pode desenvolver-se mediante a criação de sistemas de produtos e formas autônomas, assimiláveis pela emprêsa, mediante planejamento. E que precisamos ser originalmente produtivos.

\section{Proposiçăo}

Tôda a problemática anteriormente assinalada, sua dinâmica operacional, os aspectos positivamente reflexivos de sua imagem coerente e autêntica, têm para o futuro da profissāo no Brasil e no interêsse geral que é ó da nacionalidade, uma importáncia fundamental. Tudo se liga às razões históricas do Industrial design, mas num sentido diferenciado. Esse têrmo inglés, como se sabe, não tem um correspondente perfeito em nossa língua. Por outro lado, essa profissão se desenvolveu em paises onde a evolução industrial já era uma realidade; onde a indústria se formava em bases profundamente criativas e sólida tradição artesanal. E especialmente onde já se dispunha de uma consciência tecnológica própria e ainda uma consistente formação cultural, que originava um sadio espírito de concorrência mercadológica tanto interna como externa. Lembremos, porém, que no Brasil, como é sabido em especial nas áreas de planejamento, tal estágio de de- 
senvolvimento está apenas em formação. A problemática do design, numa região não desenvolvida, mereceu o pronunciamento de Tomaz Maldonado, ex-diretor do Hochschule Für Gestaltung UIm (uma escola de design), no Congresso Internacional de Desenho Industrial (o International Council of Societies of Industrial Design realizou-se em Viena em 1965), quando êle se declarou a favor de um design diferenciado para regiōes subdesenvolvidas. "11 Podemos acrescentar que uma tal atividade no Brasil deve levar-nos a preocupar-nos com propostas de produtos capazes de absorver ampla mão-de-obra, fundamentando-se, portanto, em especial, sôbre razóes de custo social, diferentemente das origens tradicionais do design. Assim, o que nos países industrializados se constituiu em retroação positiva, com uma função mais ou menos suplementar de alimentação do processo em marcha, aqui, entre nós, significa mais um esfôrço no sentido de mobilizar o próprio sistema, contra um status contraditório, ou seja retroação negativa, origem da própria evolução. Sendo assim, se nāo é uma função alimentadora, que seja terapêutica. Mas essa versăo profissional, fruto de tão vastas argumentações conjunturais implica necessàriamente uma revisão terminológica. Essa questão levou-nos a defender, no referido seminário nacional de desenho industrial em Belo Horizonte, a tese de que o nome da profissão deve ser mudado (em portugués).

\section{Terminologia}

Sugerimos a adoção do têrmo proposição como a caracterização do design mais condizente com a realidade brasileira. Outras denominações foram estudadas: projeto, planejamento, etc. Deduziu-se que, ou já estão

11 "...Um tipo de designer que funcione como consultor de organismos oficiais para a soluçǎo de projetos de interésse social."

12 Meta - design - recentemente, um grupo de designers liderados por Andries Van Onck, na Olivetti, vem desenvolvendo estudo de programaçto aplicado ao desenho industrial. demais difundidos noutras áreas ou são redundantes em térmos da realidade presente. Ademais, não correspondem ao caráter deflagrador e de base infra-estrutural que o desenho industrial brasileiro precisa assumir pelo menos por um periodo de alguns anos. Segue-se um rápido estudo terminológico:

Atividade - proposiģăo industrial

Especificação - proposiçăo de produtos

Profissionalidade - propositor

Consultoria - assessoria proposicional

Generalização - propositoria

Observação: Alguns dicionários assim traduzem o têrmo deelgn:

Desígnio

Concepção

Destinação

Criação

Proposig̣ăo

Projeto

(outros)

Segue um quadro-síntese considerando-se a linguagem:

Industrial design - Proposição industrial Motadesign - Metaproposição. ${ }^{12}$

\section{Síntese proposicional}

Mais que a elaboração formal, a propositoria almeja a variabilidade dos fíns $\theta$ destinações diversas. Em têrmos de projeção a propositoria se assemelha a um processo de reaçăo em cadela. Objetiva-se, com isso, atribuir ao trabalho criativo maior efelto multiplicador. A atividade proposicional năo deve aprofundar-se na preciea definiçăo formal do produto, pois, como ficou visto atrás, a própria realidade empresarial não o faculta. Ela parte de um processamento formal sistêmico. As proposições produtológicas nascem das proprledades gerais de elementos formais criados. A partir da proposiçăo de um sinal básico, explora-se aquelas suas propriedades de natureza bi ou tridimensionais. Tais propriedades são de natureza geométrico-composicional, de variabilidade e mutabilidade ou propriedades físicas de equilibrio estático ou 
dinấmico, aspectos de natureza tensorial e outros. Cronológicamente, a propositoria implica redução, buscando a maior valorização do tempo criativo, pela conseqũente simplificação do elemento proposto; é forçoso criar - máximo com o mínimo de trabalho empregado (operacionalidade criativa ou proposicional). Um processamento formal sistémico se faz na razão direta da necessidade de aceleração do desenvolvimento industrial. Uma de suas caracteristicas fundamentais $\theta$ a possibilidade que o mesmo deve apresentar de poder assimilar-se a produtos diferentes. A cada processo formal sistemico deve corresponder uma civilização de produtos. A semelhança dos gêneros topológicos, 13 as formas sofrerão de identidade dentro do grupo da referida composição. Para o empresariado significará múltiplas aberturas produtológicas e ampla diversificação. A proposiçăo de um sistema produtológico é um induto ao complexo industrial que o absorverá. E um modélo concentrado passivel de ser difratado (uma noção baseada nas idéias de Fred W. Riggs). ${ }^{14}$

\section{Nota sóbre a sintese proposicional}

O Centro Acadêmico Administração de Emprêsas (CAAE) da Escola de Administração de Emprésas de São Paulo, da Fundação Getúlio Vargas, exibiu, em outubro de 1970, uma pesquisa do autor dêste artigo, constando de um desenho multicomposicional: uma forma triangular (figura 2) permite a determinação de uma grande variedade de composições diferentes e admite aplicação em produtos variados. A construção désse sinal

13 Topologia - ramo avançado das matemáticas, chamada também geometria de lugar $\theta$ relaçбes. Identifica formas e espaços a partir de certas propriedades características: assim identificam-se formas de $0,1,2,3, n$ gêneros. A esfera como o cubo, por exemplo, sáo de género 0 . O toro ou anel circular é do genero 1 , e assim por diante.

14 Vide Administraçăo nos paises en desenvolvimento. Río de Janelro, Fundaçáo Getúlio Vargas, p. 26 a 31.

15 Patente requerida pelo autor ao DNPI (Departamento Nacional de Propriedade Industrial), publicada no Diárlo Oficlal da Unitáo em 19/03/1969, termo 175.337. básico é feita pela concordância de arcos de círculo, que obedecem à relação $r, 2 r, 4 r$. A pesquisa tridimensional resultou na construção de várias formações estruturais, do que é um testemunho a escultura apresentada no início do artigo. Ali revelou-se um fato indiscutivel: ésse triângulo surge sempre com o vazio ou intersticio, quando se organizam determinados agrupamentos de formas diferentes e posições relativas. Ele 6 o mesmo para formaçőes volumótricas diferentes, sólidos semi-arredondados, entremeados de esferas, ou da mesma forma familiar, como o elipsóide e outros. 15

Tal propriedade faculta inúmeras aplicaçoses industriais, para o que se torna necessário o desenvolvimento de projetos especificos, em produtos ou processos, sistemas de moldes ou matrizes. O autor afirma ter chegado a tal conclusão extrapolando os elementos: se agrupamentos formais determinam complexos intersticiais, estes podem ser organizados de maneira a determinar aglomerados de formas diferentes.

\section{Conclusto}

A propositoria será essa atividade indireta, a omissto de sistemas. Mas essa atuação deve encontrar um ambiente favorável, uma situação propícia, uma disposição empresarial para aceitar e digerir. Ressalta, aqui, a importancia do anteriormente referido programa de implantaçăo da criatividade ampla, que chamamos infra-estrutura de design. Este doravante em nosso trabalho será substituido definitivamente pelo têrmo proposlçŭo. Uma criatividade ampla, clbernetizada pela propositoria tem êste sentido maior: a estimulaçăo do almejado propósito de conduzir as populações àquela situação ideal de consumidores potenciais de inovações. Sugerimos, nesse caso, a adoção de um slogan objetivo a ser colocado sómente em produtos originados de criatividade nacional. No mais, determinar diretrizes, roteiros, condiçóes básicas, prognósticos, estabelecer alternativas 
- metodizar estratègicamente através do próprio projeto as condições ideais para a formação de grupos empresariais, quando a proposição assim o justificar. Também devese estabelecer as bases para o futuro projeto especifico de design. E que, para melhor compreensāo de sua amplitude, a propositoria pode ser concebida ao nivel das atividades de planejamento urbano. Portanto, a propositoria industrial deve ser efetivada em equipes, onde além do propositor, contar-se-á com administradores, economistas, engenheiros de produto e operação, comunicadores industriais e publicistas, arquitetos, e sociólogos, dentre outros agentes de industrialização. Foi com êsse objetivo que criamos em Belo Horizonte, em 1966, o Instituto de Planejamento $e$ Produtos Industriais (I.P.P.I), uma cooperativa de profissionais nas áreas apontadas e é o que pretendemos fazer futuramente em São Paulo.
Mas tudo ainda depende de um esfôrço de abertura, tal como o fazemos agora nesta revista, pois é verdade que ainda dependemos da compreensão nacional para a nova profissão. Torna-se necessário inocular o sistema, a realidade económico-social e cultural, instalando, por assim dizer, uma nova realidade paralelamente; 0 que possibilitará realimentação efetiva, tal como no binômio tecnologia-criatividade. Assim, a propositoria tem uma importância estratégica considerável. Ela possibilitará partir de um transcendentalismo, buscando atingir, em futuro próximo, a imanência substantiva.

Estamos efetivando agora numa pesquisa, objetivando uma colocação ampla da propositoria ao nivel do desenvolvimento global, a sua conceituação extenșa, numa área ambigua: a mobilizaçāo de empreendimentos especificos, que será assunto de um próximo artigo. Omitimos aqui essa parte do trabalho
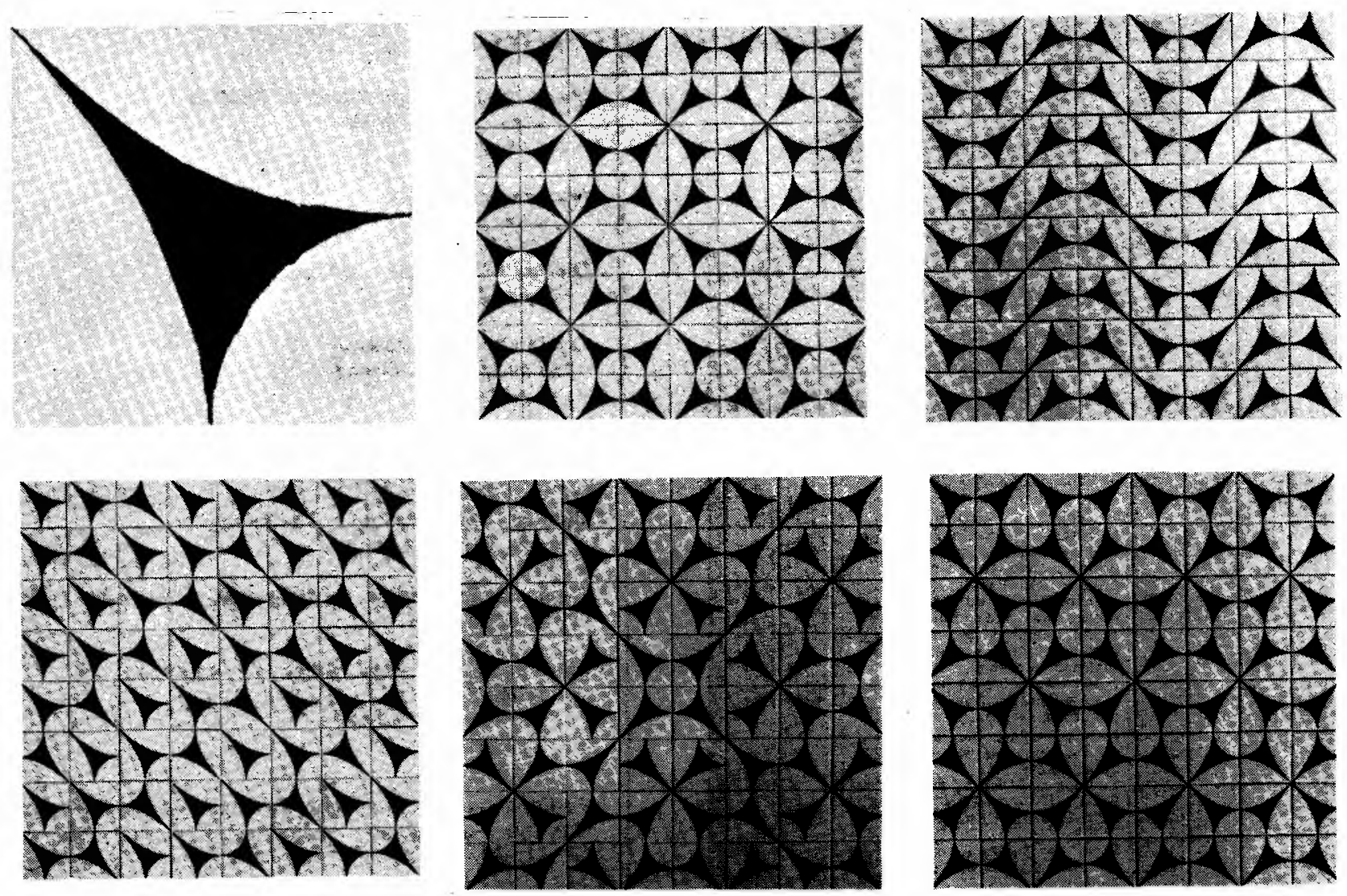
a fim de năo tornar este artigo demasiado longo neste número da revista. Mas, num rápido enfoque, queremos assinalar ainda 0 interêsse, que a nosso ver, representaria para - Brasil a implantação de um sistema de Agências de Desenvolvimento Industrial, tal como ocorre em alguns paises preocupados em vencer o subdesenvolvimento. Embora em nosso país a realidade seja um pouco diferente e de características muito próprias, citamos o livro Comunicação de idéias industriais, de Jean Marie Ackerman, como um bom ponto de partida para a formulação de um programa de comunicação industrial; é uma obra simples, mas objetiva, que pode dar ao leitor uma idéia inicial do nosso ponto de vista a respeito. Diremos que, à luz da proposiforia, as atividades dos agentes de desenvolvimento industrial assumem uma enorme amplitude, pois os processos e métodos assinalados por Ackerman são de cunho pessoal, semi-artesanais, diretos e próprios para regiōes subdesenvolvidas. $O$ Brasil, entretanto, malgrado os desequilibrios regionais, posslvelmente já admite uma ação numa dimensão maior, ampla; uma ação que pode ser desenvolvida hoje pelo melhor uso dos modernos meios de comunicação.

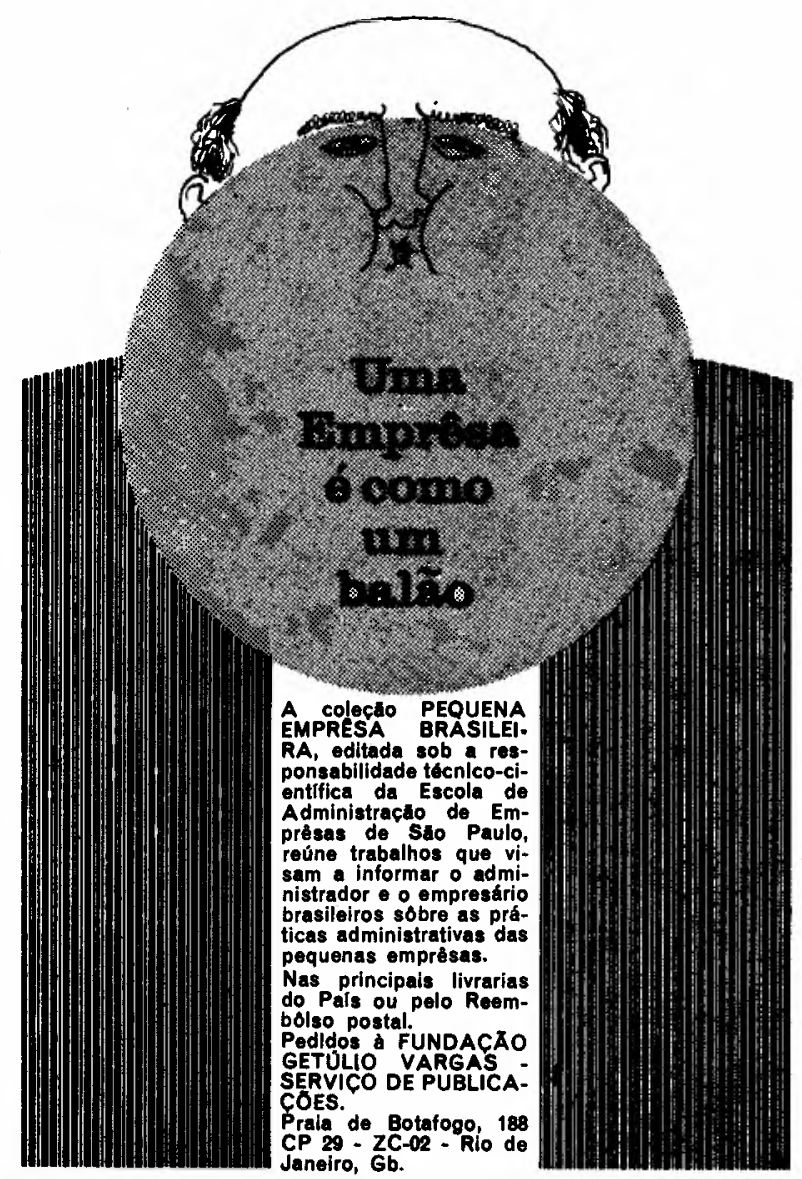

\section{PROXIMOS LANCAMENTOS DA FUNDAÇAO GETÓLIO VARGAS}

- Estudo da Administração Pública Dwight Waldo 2ạ ediçăo

Introduçlio Administraçióo Públlica Pedro Muños Amato 2* ediçăo

Orçamento Público Jesse Burkhead

Direito do Trabalho (2: ediçăo) Délio Maranhåo

Contabilidade Induatrial Salvador Chevitarese $3^{a}$ ediçăo

Planejamento Governamental Jorge Gustavo da Costa

Custos - Um Enfoque Adminiatrativo G. S. Guerra Leone

Gerencla Economica de Estoques e Compras Joary Correa

Introduçlo Teorla Geral de Adminlatraçăo Pública

Pedro Muñoz Amato

29 edicto

Pedldos para a Fundaçăo Getúlio Vargas, Serviço de Publicaçర̃es, Praia de Botafogo. 188, CP 21.120, ZC-05, Rio, GB. 